\title{
Enhancement of Antimicrobial and Antitumor Activities of Zinc Nanoparticles Biosynthesized by Penicillium chrysogenum AUMC 10608 Using Gamma Radiation
}

\author{
Manal Maher Housseiny", Eman Zakaria Gomaa \\ Biological and Geological Sciences Department, Faculty of Education, Ain Shams \\ University, Cairo, Egypt.
}

\begin{abstract}
A $\mathrm{N}$ ECO-FRIENDLY protocol for the biosynthesis of extracellular zinc nanoparticles (ZnNPs) by Penicillium chrysogenum was performed. The formation of ZnNPs was observed by the formation of white aggregates of ZnNPs and confirmed by UV absorption spectrum at $340 \mathrm{~nm}$. The synthesized ZnNPs were also characterized by High resolutiontransmission electron microscope (HR-TEM), dynamic light scattering (DLS) and fourier

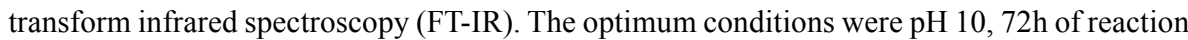
between culture filtrate $(\mathrm{CF})$ and $1 \mathrm{mM}\left(\mathrm{ZnSO}_{4}\right)$ solution with (6:1) ratio. Exposure of $\mathrm{ZnNPs}$ to gamma radiation showed an increase in the absorption band intensities when compared to the non irradiated sample. Samples of ZnNPs exposed to 20kGy dose recorded the greatest antimicrobial effect. The study of its antitumor activity against human breast carcinoma (MCF-7) and colon carcinoma cells (HCT-116) was performed. The $\mathrm{IC}_{50}$ values of (MCF-7) were $373 \mu \mathrm{g} / \mathrm{ml}$ and $>500 \mu \mathrm{g} / \mathrm{ml}$, while of (HCT-116) were 226 and $317 \mu \mathrm{g} / \mathrm{ml}$ for irradiated and non irradiated samples, respectively. TEM and DLS showed the formation of spherical monodispersed $\mathrm{ZnNPs}$ from 9 to $17 \mathrm{~nm}$ with a mean of $13 \mathrm{~nm}$ for the irradiated sample exposed to $20 \mathrm{kGy}$. The current research provided an insight on using $\gamma$-radiation as a highly efficient and inexpensive tool for the enhancement of antimicrobial and antitumor effects of nanoparticles against infectious and tumor diseases.
\end{abstract}

Keywords: Biosynthesis, Zinc nanoparticles, Gamma radiation, Antimicrobial activity, Antitumor.

\section{Introduction}

Nanoparticles synthesis is amongst the most studied topics in biology, chemistry and physics. They have unique optical, magnetic, electronic and chemical properties (Schauermann et al., 2013). Nanoparticles have many applications such as detection of proteins, biomolecules labeled with fluorescent nanoparticles drug, bio-detection of pathogens, tissue engineering probing of DNA structure, tumor destruction and separation of biological, antimicrobials and anti-insect molecules (Gong et al., 2007 and Sahayaraj \& Rajesh, 2011).

Different synthesis procedures for metal nanoparticles preparation (Ostrovsky et al., 2009) can be used; each method has its own merits and demerits. Biological methods are often preferred as they are safe, non-toxic, clean, biocompatible and environmentally acceptable (Jones et al., 2008).
Biological resources including plants, algae, yeast, viruses, fungi and bacteria can be used for the biosynthesis of intracellular and extracellular nanoparticles (Thakkar, 2010). They have best properties of oxidizing/reducing metal ions into metallic/oxide nanoparticles so that functioning as nano-factories (Noorjahan, 2015) because of their chemical constitutions (or metabolic status) which provides them able to withstand such environmentally diverse conditions. In particular, fungi have advantages over bacteria and algae, because of their high metal tolerance, economic viability, easy to scale-up and handling of biomass, low cost downstream processing, intracellular metal uptake capabilities, required simple nutrient as well as possess high wall-binding capacity (Padmavathy \& Vijayaraghavan, 2008).

Notably, the antimicrobial activity of zinc nanoparticles has become of great concern. Their inhibitory effect on both fungal and

\footnotetext{
"Corresponding author email: manal_maher2@yahoo.com

Tel.: 01062072725

DOI: $10.21608 /$ ejbo.2019.5492.1223

Edited by: Prof. Dr. Salama A. Ouf, Faculty of Science, Cairo University, Giza 12613, Egypt.

(C)2019 National Information and Documentation Center (NIDOC)
} 
bacterial species has been recently reported and exhibited the best activity compared to all studied metal nanoparticles (Azam et al., 2012). Zinc nanoparticles have been proved to possess pronounced antimicrobial activities than larger particles; considering the fact that the small size (less than 100nm) and the high surface-to-volume ratio of NP allow better interaction with bacteria (Singh et al., 2014). Moreover, the antimicrobial properties of zinc nanoparticles are highly affected by its physicochemical properties (Nicole et al., 2014).

There is an urgent need to discover new antitumor agents that are able to target cancer cells. Nowadays there is a great attention on nano-materials and their successful use in cancer treatment regimens. Moreover, Zinc nanoparticles have multiple properties that are useful for biomedical applications and appear to have observable anticancer cytotoxicity actions (John et al., 2010).

The aim of the present study was the green biosynthesis of zinc nanoparticles due to its large band width and high exciting binding energy as well as its potential applications like antibacterial, antifungal, anti-diabetic, anti- inflammatory, wound healing, antioxidant and optic properties. Then we focused on the enhancement of both antimicrobial and antitumor activities of these zinc nanoparticles and the comparison between its characteristics before and after exposure of $(50 \mathrm{ml}$ media containing $1 \mathrm{ml}$ fungal spore suspension + ZnNPs) to gamma radiation.

\section{Materials and Methods}

Biosynthesis of zinc nanoparticles

The fungus Penicillium chrysogenum was isolated from Egyptian soil and cultured over Czapek (CZ), Potato Dextrose Agar (PDA) and malt extract agar media, then the colors of the Penicillium isolate on the various media and their morphological features under a light microscope were used to be identified according to the references of Ainsworth (1971) and Pitt (1979) by Assiut University Mycological Center (AUMC) as Penicillium chrysogenum AUMC 10608 which was used throughout this work for the biosynthesis of zinc nanoparticles using adopting method suggested by Waghmare et al. (2011) with some modifications.
For the biosynthesis of metal zinc nanoparticles (ZnNPs), triplicate sets of $250 \mathrm{ml}$ flasks, each containing $50 \mathrm{ml}$ of the Czapek's medium, pH 5.6 were used and inoculated with $1 \mathrm{ml}$ of fungal spore suspension from 4-days-old cultures. The cultures were incubated at $28^{\circ} \mathrm{C}$ on a rotary shaker adjusted at $150 \mathrm{rpm}$ for $96 \mathrm{~h}$. The mycelial mass was separated from the culture broth by sterile filter paper and centrifuged at $10,000 \mathrm{rpm}$ for $20 \mathrm{~min}$, and then the extracellular fungal filtrate was used as a reducing system for the biosynthesis of $\mathrm{ZnNPs}$ from $\mathrm{ZnSO}_{4}$.

Ten $\mathrm{ml}$ of culture filtrate were mixed with $100 \mathrm{ml}$ of $1 \mathrm{mM}$ of Zinc Sulphate $\left(\mathrm{ZnSO}_{4}\right)$. The $\mathrm{pH}$ of the mixture was maintained at 10 . Further, all the mixtures were placed in a $150 \mathrm{rpm}$ rotating shaker at $28^{\circ} \mathrm{C}$ for $72 \mathrm{~h}$ duration. In this process metal nanoparticles were produced through reduction process (Rajamanickam et al., 2012).

The resulted white precipitate was centrifuged at $15,000 \mathrm{rpm}$ for $5 \mathrm{~min}$ and washed twice with sterile de-ionized water to remove the residual biological molecule then dried at $60^{\circ} \mathrm{C}$ overnight. The process of centrifugation and redispersion in sterile deionized water was repeated twice to obtained better separation of nanoparticles (Nagarajan \& Kuppusamy, 2013). Further, the powder of metal nanoparticles were mixed with $10 \mathrm{ml}$ deionized water and subjected for characterization. The un-inoculated set was maintained as control.

Optimization of reaction conditions for ZnNPs biosynthesis

The effect of different factors such as, $\mathrm{pH}(5$, $6,7,8,9,10$ and 11), exposure time to substrate ( 2 to 6 days) and concentration of zinc sulphate solution (1, 2 and $3 \mathrm{mM})$ were studied. Finally, concentration ratio of culture filtrate $(\mathrm{CF})$ to zinc sulphate was optimized with increasing concentration of $\mathrm{CF}$ to zinc sulphate solution at ratios of $(1: 1,1: 2,1: 3,1: 4,1: 5$ and 1:6) and the concentration of zinc sulphate to $\mathrm{CF}$ at ratios of (1:1, 1:2, 1:3, 1:4, 1:5 and 1:6). For studying each factor, the absorbance of the resulting solutions was measured spectrophotometrically from 300 to $800 \mathrm{~nm}$ using a double beam spectrophotometer at a resolution of $1 \mathrm{~nm}$.

\section{Characterization of zinc nanoparticles}

Various properties of the synthesized zinc oxide nanoparticles were investigated. 
Visual observations

Reaction mixture used for biosynthesis of nanoparticles was observed for visual white precipitate formation after $12,24,48$ and $72 \mathrm{~h}$.

\section{UV-visible spectroscopy analysis}

Zinc nanoparticles were characterized separately by measuring the ultraviolet-visible absorbance spectrum of the solution using a UVvis spectrophotometer (V-670 UV-VIS, JASCO, Japan). Zinc nanoparticles were scanned for the spectrophotometric analysis keeping the distilled water as a blank and maximum absorbance was determined (Naik et al., 2013). The scanning range for all the samples was maintained from 300 to $800 \mathrm{~nm}$ using a double beam spectrophotometer at a resolution of $1 \mathrm{~nm}$.

High resolution transmission electron microscopy (HR-TEM) and dynamic light scattering (DLS)

Morphology and size of the ZnNPs were investigated at Egyptian Petroleum Research Institute (EPRI), Analysis \& Evaluation Department, Nanotechnology Centre by (JEOL JEM-2010, 200kv) HR-TEM and dynamic light scattering "DLS" Zetasizer ZS (Malvern, UK). For the analysis of TEM, a drop of ZnNPscontaining aqueous solution was directly placed onto a carbon coated copper grid and allowed to air dry completely prior to TEM observations. The interaction of the electrons transmitted through the specimen resulted in the formation of an image which is then magnified and focused onto an imaging device. The film on the TEM grids were allowed to dry; the extra solution was removed using a blotting paper.

\section{FTIR spectroscopy analysis}

The FTIR spectrum of ZnNPs was analyzed using Perkin Elmer Fourier transform infrared (FTIR) spectrophotometer (Jasco FTIR- 6100, Japan) operated at resolution of $4 \mathrm{~cm}^{-1}$. The spectrum was recorded at a wave range of 400$4000 \mathrm{~cm}^{-1}$ (Aguilar-Méndez et al., 2011).

\section{Irradiation process}

The Indian Gamma cell (Ge 4000A) was used as a gamma-ray source with a dose rate of $1.338 \mathrm{kGy} / \mathrm{h}$ at a temperature of $30^{\circ} \mathrm{C}$. The $\mathrm{ZnNPs}$ samples had received the following irradiation doses: 5, 10, 15, 20, 25 and 30kGy .The prepared samples were put in the gamma cell in the manner that each sample was subjected to the same gamma dose.
Antimicrobial activity of zinc nanoparticles and MIC determination

Antimicrobial activities of optimized ZnNPs produced from Penicillium chrysogenum towards nine fungal pathogens; Aspergillus flavus, A. ochraceous, A. terreus, Fusarium solani, F. oxysporum, F. nygamai, Trichoderma viride, T. harzianum and T. longibrachiatum and ten bacterial pathogens; Bacillus subtilis NCTC 10400, Bacillus licheniformis ABRII6, Bacillus sp. 2BSG-PDA-16, Bacillus sp. DV2-37, Staphylococcus epidermidis ATCC 12228, Streptococcus pneumoniae ATCC 6303, Escherichia coli NCTC 10418, Proteus vulgaris ATCC 13315, Pseudomonas aeruginosa ATCC 10145 and Salmonella typhi NCIMB 9331 were studied before and after exposure to gamma irradiation. They were cultured on Czapek's medium in case of fungi and nutrient broth for bacterial species then, well diffusion assay (Perez et al., 1990) was performed. The MICs determinations were performed in duplicate using serial two-fold dilutions of $\mathrm{ZnNPs}$ in concentrations ranging from $1-20 \mu \mathrm{g} / \mathrm{ml}$, then, plates were incubated at $28^{\circ} \mathrm{C}$ for 7 days in case of fungi and at $37^{\circ} \mathrm{C}$ for $24 \mathrm{~h}$ in case of bacterial pathogens. The MIC of zinc nanoparticles was determined as the lowest concentration that inhibited the visible growth of the microbial pathogens. Each experiment was repeated three times and the mean diameters of the inhibition zones were recorded in millimeters.

\section{Antitumor activity}

The cytotoxicity potential of the synthesized ZnNPs was studied against colon (HCT-116) and human breast (MCF-7) carcinoma cell lines obtained from the American Type Culture Collection (ATCC, UAS). The cell viability was measured using MTT assay which is based on the reduction of the tetrazolium salt by actively growing cells (Renugadevi \& Venus, 2012). The cells were propagated in Dulbecco's modified Eagle's medium (DMEM) supplemented with $10 \%$ heat-inactivated fetal bovine serum, $1 \%$ L-glutamine, HEPES buffer and $50 \mu \mathrm{g} / \mathrm{ml}$ gentamycin. All cells were maintained at $37^{\circ} \mathrm{C}$ in a humidified atmosphere with $5 \% \mathrm{CO}_{2}$ and were sub cultured two times a week.

For cytotoxicity assay, the cells were seeded in 96-well plate at a cell concentration of $1 \times 10^{4}$ cells per well in $100 \mu \mathrm{l}$ of growth medium. Control cells were incubated without test sample and with 
or without DMSO. After incubation of the cells at $37^{\circ} \mathrm{C}$, various concentrations of ZnNPs (3.9, $7.8,15.6,31.25,62.5,125,250$ and $500 \mu \mathrm{g}$ ) were added, and the incubation was continued for $48 \mathrm{~h}$ then viable cells yield was determined by a colorimetric method (Gomha et al., 2015).

After the end of the incubation period, media were aspirated and the crystal violet solution (1\%) was added to each well for at least $30 \mathrm{~min}$. The stain was removed and the plates were rinsed using tap water until all excess stain is removed. Glacial acetic acid (30\%) was then added to all wells and mixed thoroughly, and then the absorbance of the plates were measured after gently shaken on Micro plate reader (TECAN, Inc.), using a test wavelength of $490 \mathrm{~nm}$. All results were corrected for background absorbance detected in wells without added stain. Treated samples were compared with the cell control in the absence of the tested compounds. All experiments were carried out in triplicate. The optical density was measured with the micro plate reader (SunRise, TECAN, Inc, USA) to determine the number of viable cells

The percentage of cell viability was calculated as follows:

Cell viability $(\%)=(\mathrm{OD}$ experimental group $/ \mathrm{OD}$ control group) $\times 100$.
The $50 \%$ inhibitory concentration $\left(\mathrm{IC}_{50}\right)$, the concentration required to cause toxic effects in $50 \%$ of intact cells, was estimated from graphic plots of the dose response curve for each conc. using Graph pad Prism software (San Diego, CA. USA). The lower the $\mathrm{IC}_{50}$ value indicates high antitumor capacity.

\section{Statistical analyses}

All assays were carried out in triplicate, and the results were presented as mean \pm SD "standard deviation". The experimental data were analyzed using SPSS 14. Statistical significance was accepted at a level of $\mathrm{P}<0.05$.

\section{Results and Discussion}

\section{Biosynthesis of zinc nanoparticles}

The present study approaches towards the ecofriendly biological synthesis of zinc nanoparticles. However, development of simple and eco-friendly route would help in promoting further interest in the synthesis and application of $\mathrm{Zn}$ nanoparticles. Penicillium chrysogenum was selected for this work on the basis of its great and rapid biosynthetic potentiality of zinc nanoparticles. As the Fig. 1 shows, the characteristic absorption peak at $340 \mathrm{~nm}$ in UV-vis spectrum confirmed the formation of ZnNPs which corresponds to spectrum plasmon resonance (SPR) of ZnNPs established previously (Sangeetha et al., 2011).

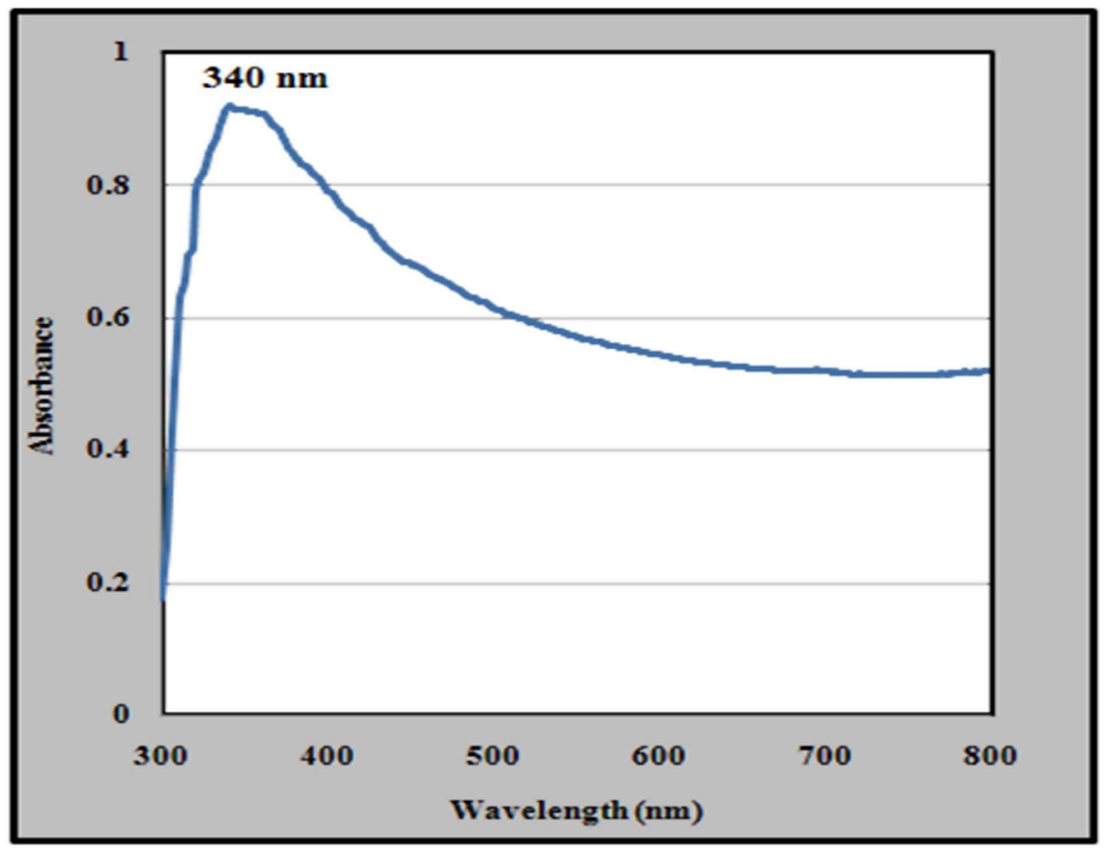

Fig. 1. UV VIS-spectrum of zinc nanoparticles biosynthesized by Penicillium chrysogenum. 
For zinc nanoparticles green synthesis from fungi, precursor compound of each metal of interest was added. Selection of compounds was based on their ionic potential in water with fungal extracellular enzymes. Sulfates of the metal were selected for the synthesis of $\mathrm{Zn}$ nanoparticles on the basis of their ionic strength (Ahmad et al., 2003). This is in accordance with Premanathan et al. (2011) who reported that Fusarium oxysporum secretes sulfate reductase enzymes when exposed to aqueous $\mathrm{MSO}_{4}$ (where $\mathrm{M}=\mathrm{Cd}, \mathrm{Pb}, \mathrm{Mn}$ and $\mathrm{Zn}$ ) solution resulting in the formation of extremely stable metal oxide nanoparticles in the solution.

\section{Optimization of ZnNPs biosynthesis}

The present work highlights various parameters affecting the synthesis of nanoparticles by green nano-biotechnology. Major parameters affecting the synthesis of nanoparticles including their size, shape and monodispersity, mainly depends on the physical and chemical parameters which mainly includes $\mathrm{pH}$, exposure time to substrate, concentration of zinc sulphate and concentration ratio of culture filtrate to zinc sulphate.

$$
p H
$$

$\mathrm{pH}$ is one of the key factors playing a major role in nanoparticles synthesis. There is no particles formation at acidic $\mathrm{pH}$ 5. White precipitate formation was rapid at alkaline $\mathrm{pH}$ 10. Agglomeration was observed at $\mathrm{pH} 11$ immediately after adding the zinc sulphate into the reaction mixture. It is clear from Fig. 2 that
$\mathrm{pH} 10$ was found to be the most suitable not only for accelerating the rate of reaction but also to substantially reduce nanoparticle size as compared to other $\mathrm{pH}$ levels.

Our results were in accordance also with the study of Baroli (2010) in which they synthesized $\mathrm{Mg}$ and $\mathrm{Fe}$ nanoparticles in different chemical environments. The majority of enzymes normally exhibit a strong dependence of activity on the $\mathrm{pH}$ of the medium (Lu et al., 2015), thus, it is important to optimize the $\mathrm{pH}$ of the reaction medium in which nanoparticle synthesizes. In the biosynthesis of $\mathrm{Zn}$ nanoparticles, concentration of hydroxide ion of the reaction medium plays an important role for nanoparticle size as our results shown in Fig. 2 which clearly indicated that $\mathrm{pH} 10$ is most suitable for $\mathrm{Zn}$ nanoparticles biosynthesis. It might be possible that $\mathrm{pH}$ specific catalytic activity of enzyme secreted from fungus depends on the $\mathrm{pH}$ changes, so catalytic efficiency of enzyme also altered.

About the effect of pH, Banu \& Rathod (2011) suggested that at lower $\mathrm{pH}$, protein structure gets affected and becomes denatured and loses its activity so, big size of NPs was observed. The reductase enzyme catalyzing the synthesis is probably deactivated gradually as the conditions become alkaline and this may be the reason of reduced synthesis and increase in size which is observed at higher $\mathrm{pH}$ values.

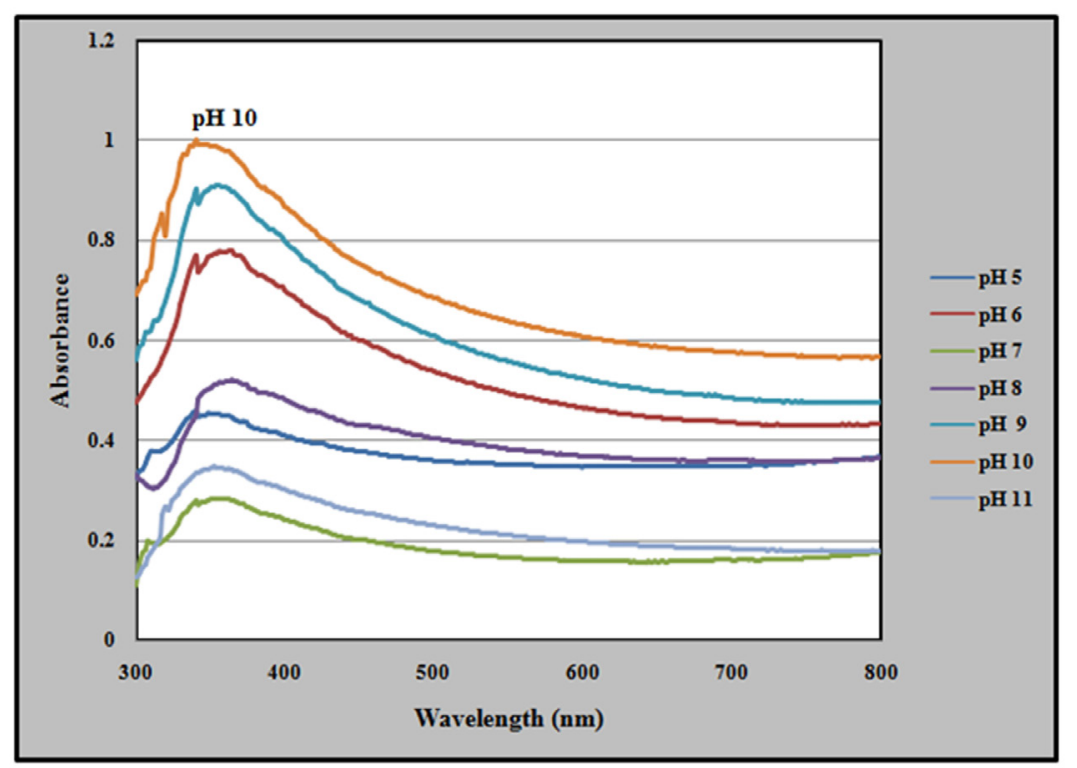

Fig. 2. UV VIS-spectra of zinc nanoparticles biosynthesized by Penicillium chrysogenum at different pH values. 
Zhang et al. (2013) stated that $\mathrm{pH}$ of the medium solution influences the texture and the size of the synthesized nanoparticles. So nanoparticle size can be controlled by changing the $\mathrm{pH}$ of the medium. Zhou et al. (2015) carried out a study in which they studied the change in shape of nanoparticles with variation in $\mathrm{pH}$, they found that Verticillium luteoablum synthesizes nanoparticles of spherical shapes of size $(<10.0 \mathrm{~nm})$ at $\mathrm{pH} 3$, but when $\mathrm{pH}$ is increases to 5 the shape obtained are hexagons, triangular and rod shaped. Further increases in $\mathrm{pH}$ that is 7 to 9 nanoparticles with irregular and undefined shapes were obtained. This is in accordance also with Sanghi \&Verma (2009) who studied the effect of $\mathrm{pH}$ on the fabrication of nanoparticles produced by Coriolus versicolor. The obtained results also suggested that reduction of metal ions were highly sensitive to $\mathrm{pH}$.

\section{Exposure time to substrate}

The optimum production of ZnNPs was achieved after $72 \mathrm{~h}$ as shown in Fig. 3 and none nanoparticles were produced up to $24 \mathrm{~h}$ of incubation period, the biosynthesis of ZnNPs was detected only after $36 \mathrm{~h}$ of incubation. It was also observed that further incubation beyond $72 \mathrm{~h}$, neither reduced the size of nanoparticles nor was economical to harvest appreciable yields. The results clearly indicated that there were best yields of nanoparticles with reduced size at $72 \mathrm{~h}$ of incubations. Therefore, for further experimentation, the incubation period was kept at $72 \mathrm{~h}$ when the fungus age was 7 days. It was found also that the size and the shape of nanoparticles varies with variation in the incubation period of reaction mixture.

It has been also found that with increasing the incubation time, the synthesis of nanoparticles also increases as reported by Li et al. (2007) who stated that the majority of nanoparticles are synthesized after $1 \mathrm{~h}$ incubation to metal containing solution and when incubation time is increases up to $24 \mathrm{~h}$, it shows the synthesis of nanoparticles of bigger sizes and this is due to the clump formation or segregation of smaller size nanoparticles. It has been also seen that with increasing the time up to 2-4 days there were alteration in the actual shape and size of the synthesized nanoparticles (Noorjahan et al., 2015).

Similarly, the characteristics of the synthesized nanoparticles were also altered with time and greatly influenced by the synthesis process and storage conditions (Xie et al., 2007). The variations in the time may occur in many ways such as particles may shrink, grow and aggregate due to long time storage that affects their potential (Boxall et al., 2007).

\section{Concentration of zinc sulphate solution}

Different concentrations of zinc sulphate were optimized for the maximum synthesis of zinc nanoparticles. Interestingly, $1 \mathrm{mM}$ concentration of zinc sulphate supported rapid formation of zinc nanoparticles whereas the peak got shifted at $2 \mathrm{mM}$ and $3 \mathrm{mM}$ concentrations (Fig. 4).

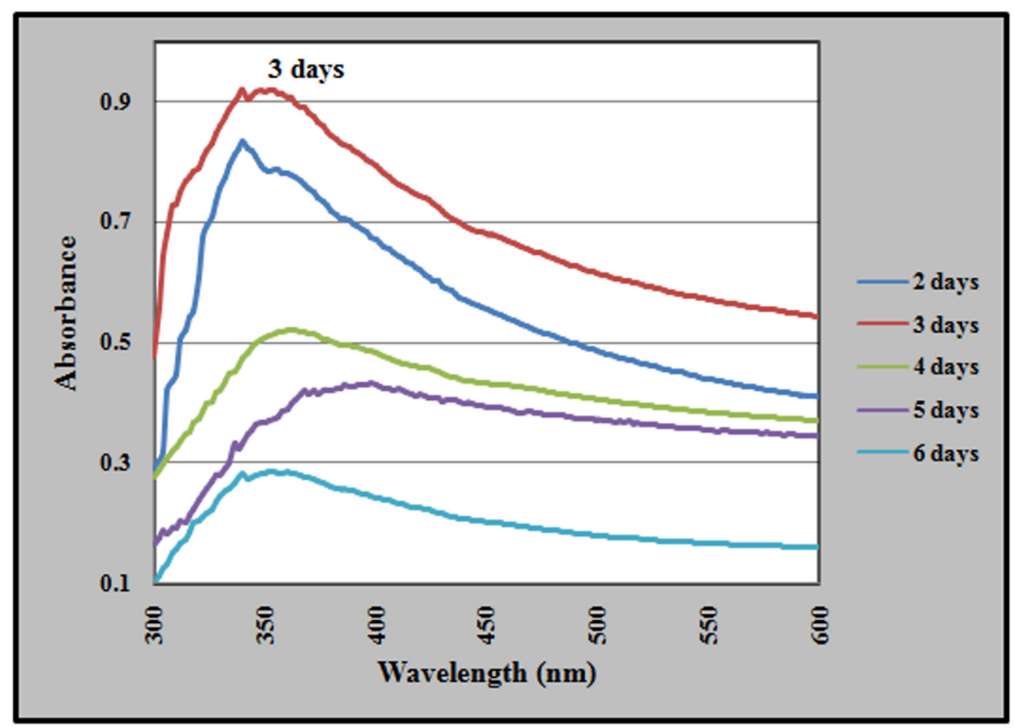

Fig. 3. UV VIS-spectra of zinc nanoparticles biosynthesized by Penicillium chrysogenum at different reaction times. 


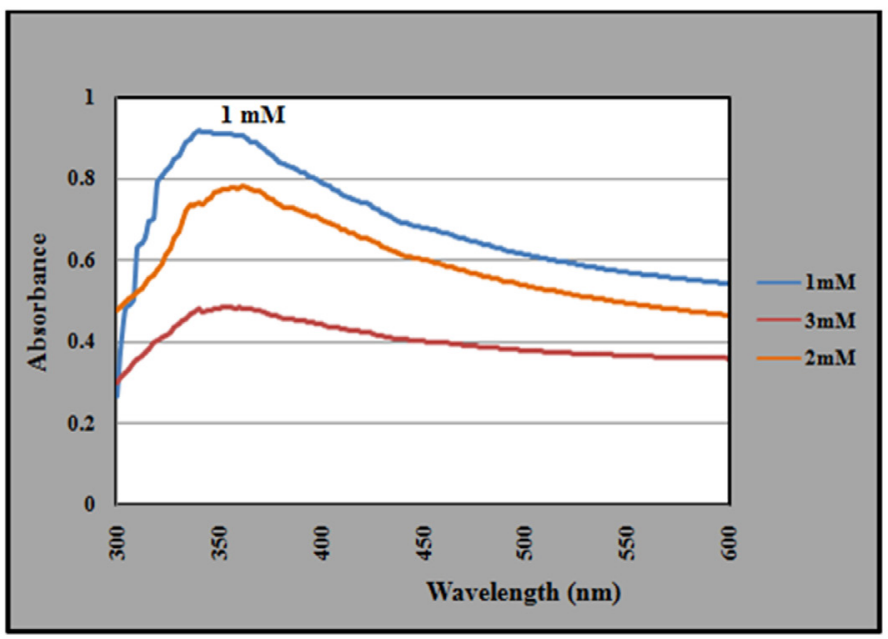

Fig. 4. UV VIS- spectra of zinc nanoparticles biosynthesized by Penicillium chrysogenum at different concentrations of zinc sulphate solution.

Results recorded showed that at lower $\mathrm{ZnSO}_{4}$ concentrations, excess enzyme may have been available within the system, but higher production may not have occurred due to lack of substrate molecules. Alternatively, the presence of substrate in the medium may also serve to induce the release of enzyme from fungi, which may in turn reduce zinc in the substrate to NPs. As more of the substrate molecules are supplied to the medium, the enzyme secretion by the fungi may proportionately increase until a threshold concentration which in this case was observed to be $3 \mathrm{mM}$. Access addition of metal ions with a concentration of $3 \mathrm{mM}$ results in the presence of very large particles exhibiting irregularly shaped that most of the cell enzymes were consumed by reduction of particles, demonstrating the high capacity of the cells for zinc reduction (Ahmad et al., 2010).

Concentration ratios of culture filtrate and zinc sulphate solution

Similarly, different concentration ratios of culture filtrate and zinc sulphate solution were also optimized for maximum production of zinc nanoparticles. Interestingly, the ratio of ( 6 culture filtrate: 1 zinc sulphate solution) was turned fast to white precipitate, indicating rapid formation of zinc nanoparticles (Fig. 5).

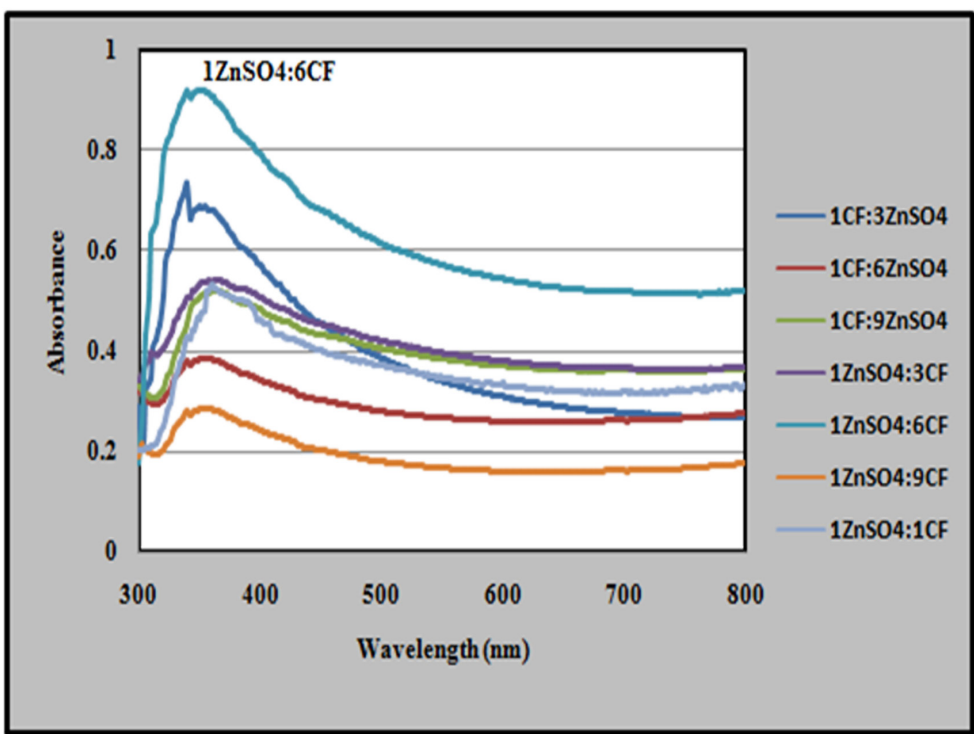

Fig. 5. UV VIS-spectra of zinc nanoparticles biosynthesized by Penicillium chrysogenum at different concentration ratios of culture filtrate (CF) and zinc sulphate. 
Notably, the concentration of metal ions also influences the synthesis of metal nanoparticles as demonstrated by Soliman (2014) and Singh et al. (2012) that at high concentration of silver ions, the shape, size and monodispersity of the nanoparticles vary from the desire nano size. As in the chemical reactions, the concentration of reactants decides the rate of reaction and also affects the size and shape of the synthesized particles. This is in accordance with Gericke \& Pinches (2006) who synthesized gold nanoparticles using Verticillium luteoalbum, the obtained results suggested that when the concentration of $\mathrm{AuCl}^{4-}$ was below $500 \mathrm{mg} / \mathrm{L}$, the size of the gold nanoparticles was slightly narrow and uniform size ranges (>20nm). Although when the concentration of $\mathrm{AuCl}^{4-}$ was increases, the size of the synthesized nanoparticles increased with increasing $\mathrm{AuCl}_{4}$ concentration. In addition, at high concentration of metal ions the aggregation of smaller particles also found Gericke \& Pinches (2006).

\section{Irradiation process}

Treatment of fungal strain (Penicillium chrysogenum) with different doses of gamma irradiation showed the maximum SPR intensity (Optical density 1.4) at 20kGy dose (Fig. 6). About the effect of gamma irradiation, it resulted in viable and stable enhanced isolate with increased production of enzymes (Dey et al., 2010). Similarly, several studies showed that gamma irradiation could change the genomic structure (Liu et al., 2009).

Immediate reduction and change in color was observed after treatment of fungal culture filtrate with different doses of gamma irradiation after mixing with zinc sulphate solution as shown in Fig. 7. This could be attributed to two mechanisms; the first is the extracellular enzymes and components of $\mathrm{CF}$ and the second is radiolytic mechanism of gamma irradiation which increased the synthesis of NPs (Misra et al., 2012). As clear in Fig. 6, the maximum SPR band intensity was at 1.4, after which the SPR band intensity decreased by increasing the irradiation dose more than $20 \mathrm{kGy}$. This may be due to the destructive impact of free radicals produced by gamma irradiation on the bioactive compounds present in the extract (ELKhatib et al., 2004).

High doses of $\gamma$-irradiation increase the nucleation rate which leads to the formation of smaller particles and the reduction reaction will prevail, thus there will be many new clusters allowing smaller ZnNPs to be formed. In contrast, the adsorption of $\mathrm{Zn}^{+}$onto clusters is predominant for low dose rate; therefore, ZnNPs will be larger. Consequently, the increase in the intensity of SPR peak is related to the increase of the concentration of ZnNPs as the dose of irradiation increases.

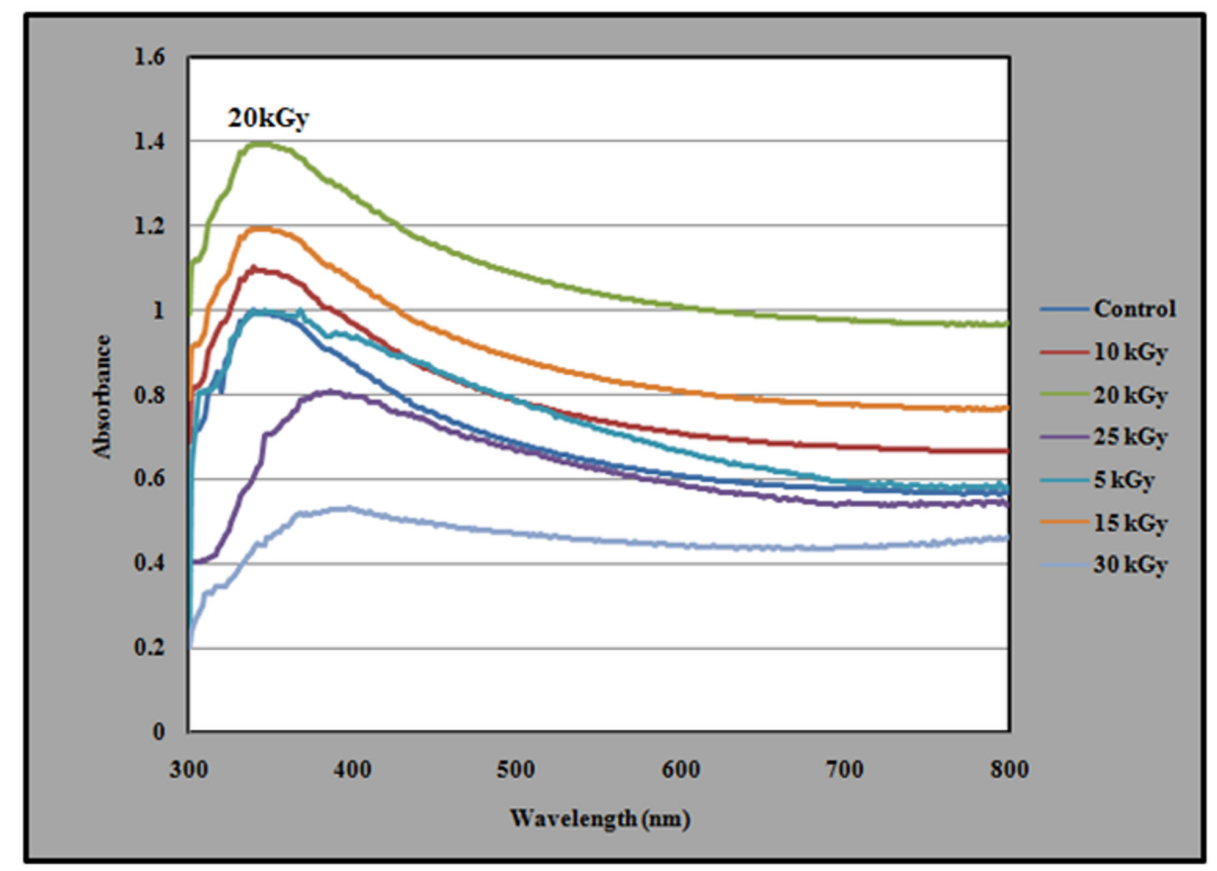

Fig. 6. UV VIS-spectra of zinc nanoparticles exposed to different doses of gamma radiation (from 5 to $30 \mathrm{kGy}$ ). 


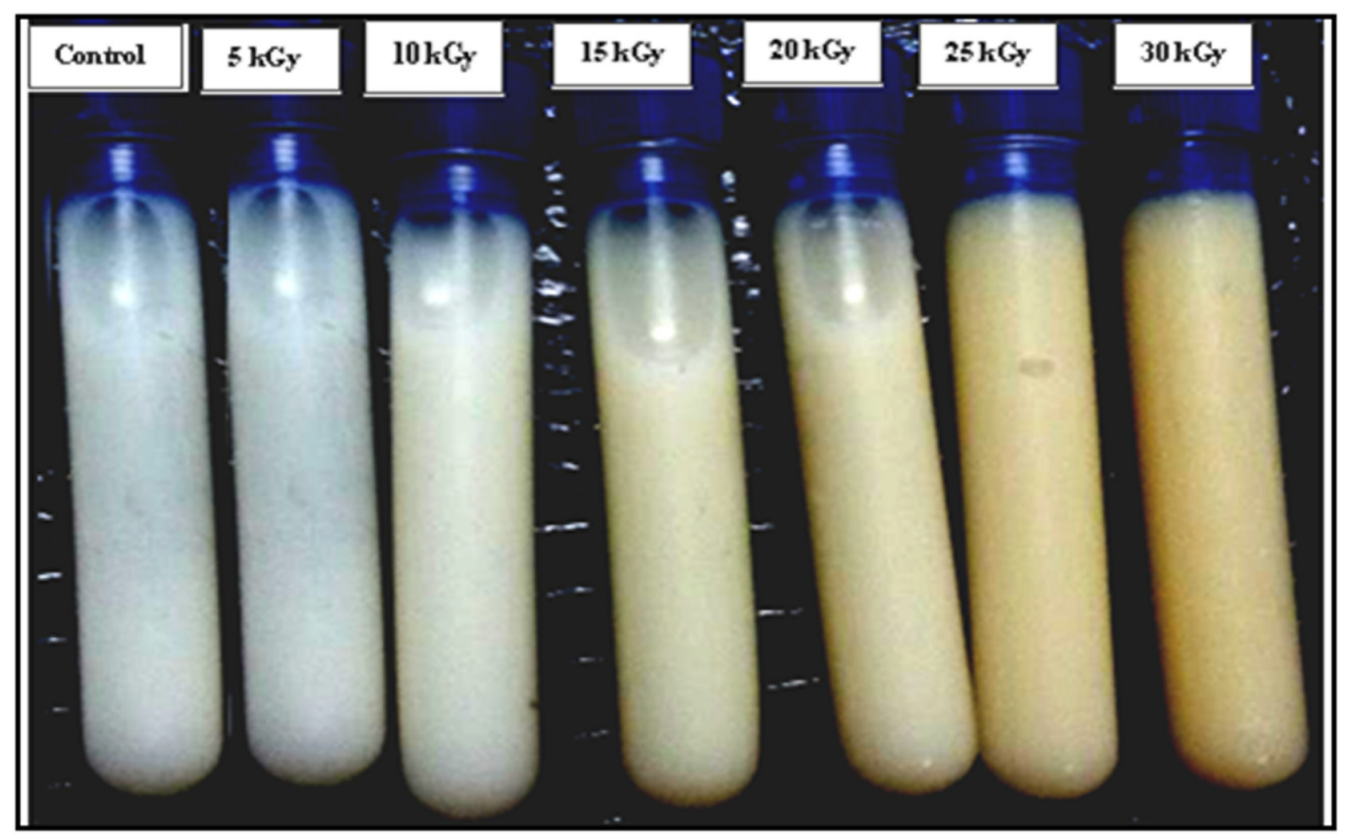

Fig. 7. Color change of zinc nanoparticles exposed to different doses of gamma radiation (from 5 to $30 \mathrm{kGy}$ ).

Characterization of zinc oxide nanoparticles synthesized by Penicillium chrysogenum

Additionally, characterization of the synthesized nanoparticles is essential for their potential use in various drug delivery and biomedical applications. The zinc nanoparticles synthesized using $P$. chrysogenum culture filtrate was characterized by UV-Visible spectrophotometer, FTIR, DLS and TEM, the results are discussed.

\section{Visual observation}

On mixing the Penicillium chrysogenum culture filtrate with the aqueous solution of zinc sulphate, the color of the culture filtrate was changed from colorless solution to turbid liquid with increasing in the turbidity as the time increased until $72 \mathrm{~h}$. This color change is an indication of zinc sulphate ions reduction by the proteins present in culture filtrate which resulted in the formation of white aggregates of zinc oxide nanoparticles as shown in Fig. 7. Changes in color intensity was also observed after exposure of ZnNPs to different doses of gamma irradiation (Fig. 8) as the color turned from white to yellow with increasing the irradiation dose.

\section{$U V$-Vis spectroscopy}

The reduction of zinc salt to their respective zinc ion was monitored by UV-Vis spectrum. The UV Vis spectra of ZnNPs were shown in Fig. 1. The maximum absorption peak of the ZnNPs was found at $340 \mathrm{~nm}$. The absorption spectra obtained was similar to that reported by Xie et al. (2007) for zinc nanoparticles. The UV/vis. spectrophotometry was also used to confirm the formation of the ZnNPs. The optical spectrum of un-irradiated biosynthesized zinc shows a broad absorption band in the visible region at $340 \mathrm{~nm}$ besides a change in the shape of absorbance peaks of $\mathrm{Zn}$ and the penicillium chrysogenum filtrate. This band is assigned as SPR of zinc NPs and is responsible for the white precipitate formation (Xie et al., 2007).

High resolution transmission electron microscope (HR-TEM) and dynamic light scattering (DLS)

Transmission electron microscopy is one of the most important conformational techniques in the current study. Distribution of NPs, morphology and control on the size play an important role in determining the NP properties so that, TEM micrographs are taken into consideration for obtaining an excellent idea from what is happening inside the matrix system. The typical TEM micrographs and the corresponding size distribution histograms of biosynthesized Zn NPs by $P$. chrysogenum before and after irradiation process by dose 20 of $\gamma$-rays (Fig. 8a and 8b). The obtained ZnNPs are predominantly spherical, poly-dispersed and compactly arranged. Most of them are roughly circular in shape with smooth edges. TEM confirm that the particles are almost spherical with non uniform thickness. 

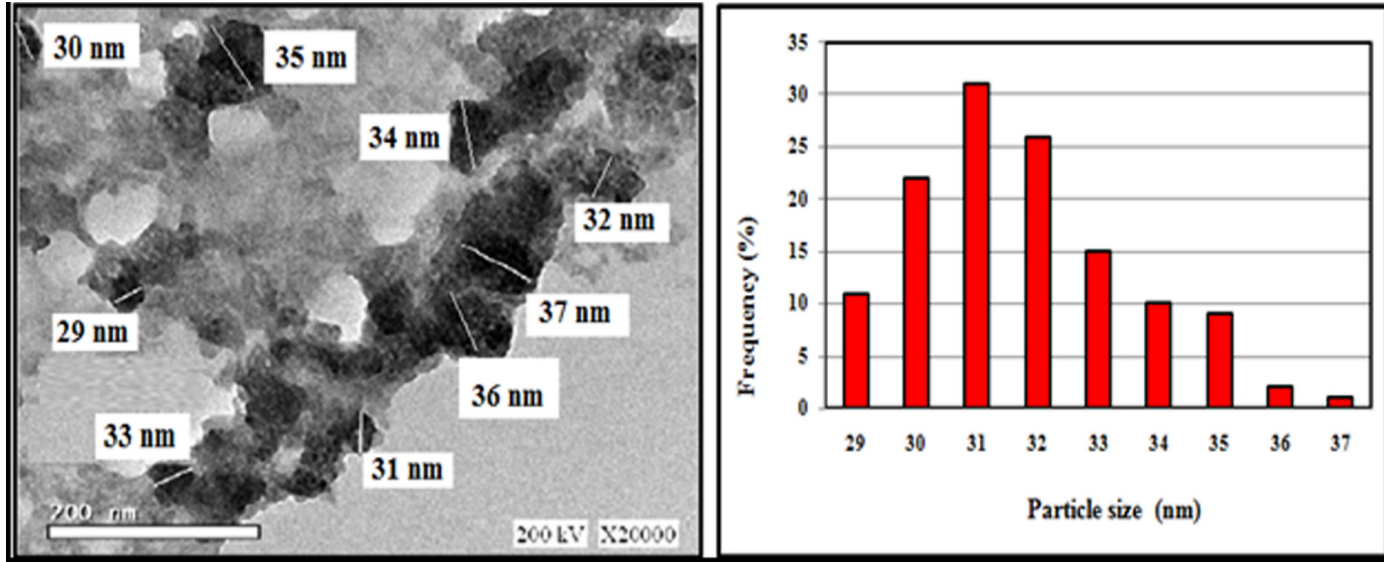

Fig. 8a. TEM image and particle size distribution of untreated zinc nanoparticles biosynthesized by Penicillium chrysogenum.
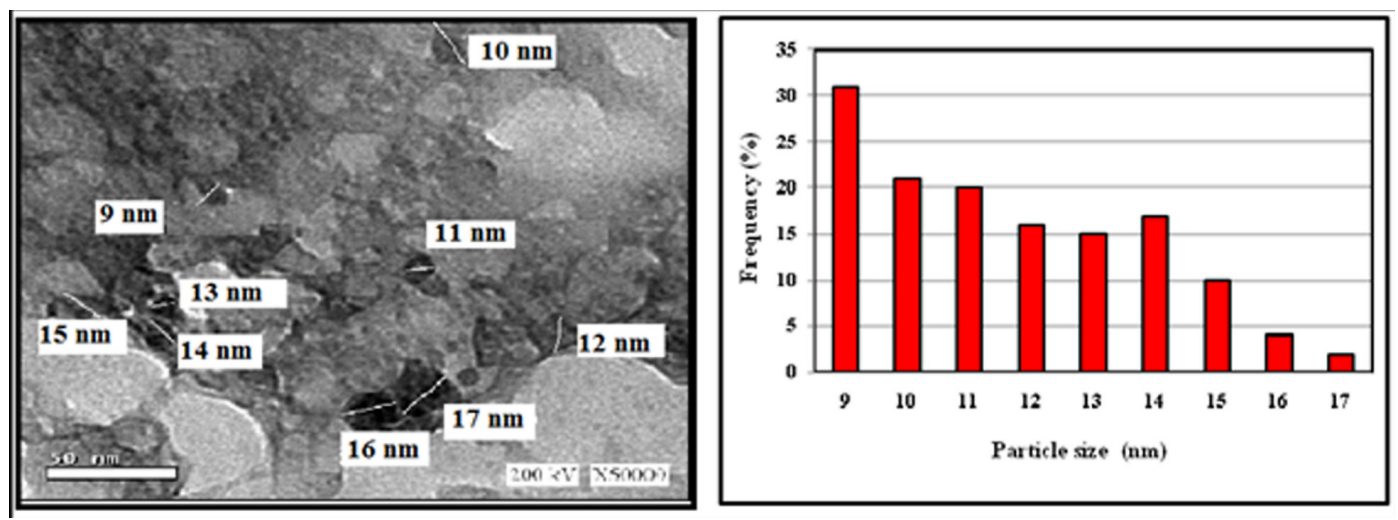

Fig. 8b. TEM image and particle size distribution of zinc nanoparticles biosynthesized by Penicillium chrysogenum treated with $20 \mathrm{kGy}$ of gamma radiation.

TEM shows average particle diameters ranging from 29 to $37 \mathrm{~nm}$ with a mean of $33 \mathrm{~nm}$ for the non irradiated ZnNPs and showed the formation of spherical monodispersed ZnNPs from 9 to $17 \mathrm{~nm}$ with a mean of $13 \mathrm{~nm}$ for the irradiated one exposed to $20 \mathrm{kGy}$. Thus, we have a wide range in the particle size distribution for biosynthesized Zn NPs. This result indicates that the particles growth rate is relatively slow as compared with the rapid $\mathrm{Zn}$ ion reduction. It is observed that the aggregation of the particles was limited and the monodispersity was enhanced (Fig. 8). Monodispersity of NPs comprises the particles uniform in shape and size. It can be directly observed from TEM micrographs that the formed Zn NPs become more uniform nano-spheres in size with $20 \mathrm{kGy}$ irradiation dose. This reflects the effective role of $\gamma$-rays in monodispersity of the prepared Zn NPs.

The results of the DLS measurement indicated a reduction in the size of ZnNPs with $\gamma$-irradiation. To the best of our knowledge, this is the first report on the reduction of $\mathrm{ZnNPs}$ diameter with $\gamma$-irradiation, and this can account for the enhanced antimicrobial activity of ZnNPs with $\gamma$-irradiation. Moreover, the irradiation dose of $\gamma$-rays is the controlling factor in determining the particle size. This is in accordance with Markushev et al. (2005) who stated that with irradiation dose increasing, the prepared particle size gets smaller and the distribution of particle size is enhanced.

\section{Fourier transform infrared (FT-IR) analysis}

The synthesized zinc nanoparticles were subjected to FTIR analysis to detect the various characteristic functional groups associated with the synthesized nanoparticles and responsible for their stabilization and coordination. The peaks indicate the characteristics functional group present in the synthesized zinc nanoparticles. FTIR analysis was measured out in order to confirm the complication between the Penicillium chrysogenum filtrate and $\mathrm{Zn}$ ions and also to identify the possible reducing and stabilizing biomolecules in the P. chrysogenum ZnNPs. The FTIR spectra recorded at room temperature in the region $400-4000 \mathrm{~cm}$ (Cai \& Singh, 2004). 
Figure 9a show that the untreated sample of zinc nanoparticle has absorption peaks in the range of $3447 \mathrm{~cm}^{-1}, 2939 \mathrm{~cm}^{-1}, 2359 \mathrm{~cm}^{-1}, 1605 \mathrm{~cm}^{-1}, 1443 \mathrm{~cm}^{-}$ $1,1385 \mathrm{~cm}^{-1}, 1356 \mathrm{~cm}^{-1}, 1184 \mathrm{~cm}^{-1}, 1156 \mathrm{~cm}^{-1}, 1116$ $\mathrm{cm}^{-1}, 830 \mathrm{~cm}^{-1}, 779 \mathrm{~cm}^{-1}, 618 \mathrm{~cm}^{-1}$ and $458 \mathrm{~cm}^{-1}$. The absorption peak at $618 \mathrm{~cm}^{-1}$ corresponds to metaloxygen ( $\mathrm{ZnO}$ stretching vibrations) vibrational mode. The peak at $3447 \mathrm{~cm}^{-1}$ indicate the presence of $\mathrm{O}-\mathrm{H}$ stretch bonding, aldehydic $\mathrm{C}-\mathrm{H}$ stretching was recorded at $2939 \mathrm{~cm}^{-1}$, carboxylic acid $\mathrm{O}-\mathrm{H}$ stretch was recorded at $2359 \mathrm{~cm}^{-1}$. The peak at $1605 \mathrm{~cm}^{-1}$ indicate the presence of $\mathrm{C}=\mathrm{C}$ aromatic stretch bonding, $1443 \mathrm{~cm}^{-1}, 1385 \mathrm{~cm}^{-1}$ and $1356 \mathrm{~cm}^{-1}$ are ascribed to the vibrational modes of aromatic nitro compounds and alkyl $\mathrm{C}=\mathrm{C}$ stretch, amide, open chain imino. The peaks at $1184 \mathrm{~cm}^{-1}, 1156$ $\mathrm{cm}^{-1}$ and $1116 \mathrm{~cm}^{-1}$ were ascribed to the stretching vibration of $\mathrm{C}-\mathrm{N}$ bond of the primary amine or to the stretching vibration of the $\mathrm{C}-\mathrm{O}$ bond of the primary alcohol. C-O-C stretch was recorded at $830 \mathrm{~cm}^{-1}$, $779 \mathrm{~cm}^{-1}, 618 \mathrm{~cm}^{-1}$ with aromatic $\mathrm{C}-\mathrm{H}$ bending. The presence of these functional makes the synthesized zinc oxide nanoparticles as effective antimicrobial agent. Our results for zinc nanoparticles were in accordance with Renuga \& Gayathri (2010) and Khadri et al. (2013).

Figure $9 \mathrm{~b}$ show that the sample of zinc nanoparticle treated with $20 \mathrm{kGy}$ has absorption peaks in the range of $3443 \mathrm{~cm}^{-1}, 2938 \mathrm{~cm}^{-1}, 2110$ $\mathrm{cm}^{-1}, 1601 \mathrm{~cm}^{-1}, 1384 \mathrm{~cm}^{-1}, 1116 \mathrm{~cm}^{-1}, 867 \mathrm{~cm}^{-1}$, $830 \mathrm{~cm}^{-1}, 779 \mathrm{~cm}^{-1}$ and $618 \mathrm{~cm}^{-1}$. It is clear that there is an appearance of some new peaks in the treated sample such as, $2110 \mathrm{~cm}^{-1}$ (in which Alkynyl stretch was recorded) and $867 \mathrm{~cm}^{-1}$ (for C-O-C stretch) and the disappearance of some peaks already observed in the untreated sample as $2359 \mathrm{~cm}^{-1}, 1443 \mathrm{~cm}^{-1}$, $1356 \mathrm{~cm}^{-1}, 1184 \mathrm{~cm}^{-1}, 1156 \mathrm{~cm}^{-1}$ and $458 \mathrm{~cm}^{-1}$.

Basavaraja et al. (2008) showed agreement with FTIR spectrum using Fusarium semitectum that the presence of amide I and amide II bands arises due to carbonyl stretch and $-\mathrm{N}-\mathrm{H}$ stretch vibrations in the amide linkage of the protein. Mahmoud et al. (2013) has a good agreement with the unit cell of the face centered cubic structure. This result showed that the protein molecules not only act as reducing agent but also act as stabilizing agent by binding the ZnNPs through free amino groups or cysteine residues or through electrostatic attraction of negatively charged carboxylate groups in extracellular enzyme filtrate from fungal mycelia. These peaks also indicated the presence of proteins and other organic residues, which might have produced extracellularly by $P$. chrysogenum (Boxall et al., 2007).

\section{Antimicrobial activity of $\mathrm{ZnNPS}$}

As shown in Table 1, zone of clearance was observed in all the fungal species except Fusarium nygamai and Rhizopus oryzae, from which it is inferred that synthesized ZnNPs have a great antifungal activity. Zones of clearance were at the maximum levels in T. harzianum $(33 \mathrm{~mm})$, Fusarium solani (30mm) and F. oxysporum (28mm) with minimum inhibitory concentration of the zinc nanoparticles $(3.5,3.8,4.5 \mu \mathrm{g} / \mathrm{ml})$, respectively. The remaining pathogens also showed moderate antifungal activities against ZnNPs.

As observed in Table 1, ZnNPs have antibacterial activities against all the tested bacterial species except Bacillus sp., Staphylococcus pneumonia, Escherichia coli and Salmonella typhi. Zones of clearance were at the maximum levels in Bacillus licheniformis (20mm), Staphylococcus epidermis (19mm) and Pseudomonas aeruginosa (18mm) with minimum inhibitory concentration of the ZnNPs $(4.0,4.5,5.8 \mu \mathrm{g} / \mathrm{ml})$, respectively.

Differences in the susceptibility of bacteria to ZnNPs were previously reported to be related to the differences in the cell wall structure, cell physiology, the degree of contact or metabolism. The variation in the MIC values in different studies may be attributed to the difference in the method used for the preparation of NP, which can affect their particle size. Several mechanisms were proposed for the antimicrobial activity of ZnNPs including the generation of reactive oxygen species and the release of toxic zinc ions which can inhibit the active transport and disturb amino acid metabolism (Yousef \& Danial, 2012 and Wang et al., 2012).

The antimicrobial activity of ZnNPs has been previously reported by Yousef \& Danial (2012) and Wang et al. (2012), however, in our study, we compare between the antimicrobial effect of non irradiated and irradiated ZnNPs exposed to different doses of gamma rays. By applying different $\gamma$ radiation doses to the preparations containing ZnNPs, the antimicrobial activity of ZnNPs was enhanced by increasing the irradiation dose until reaching $20 \mathrm{kGy}$ then decreased. This was indicated by the increase in zone diameters against the tested microorganisms (Table 1). 
$\mathbf{A}$

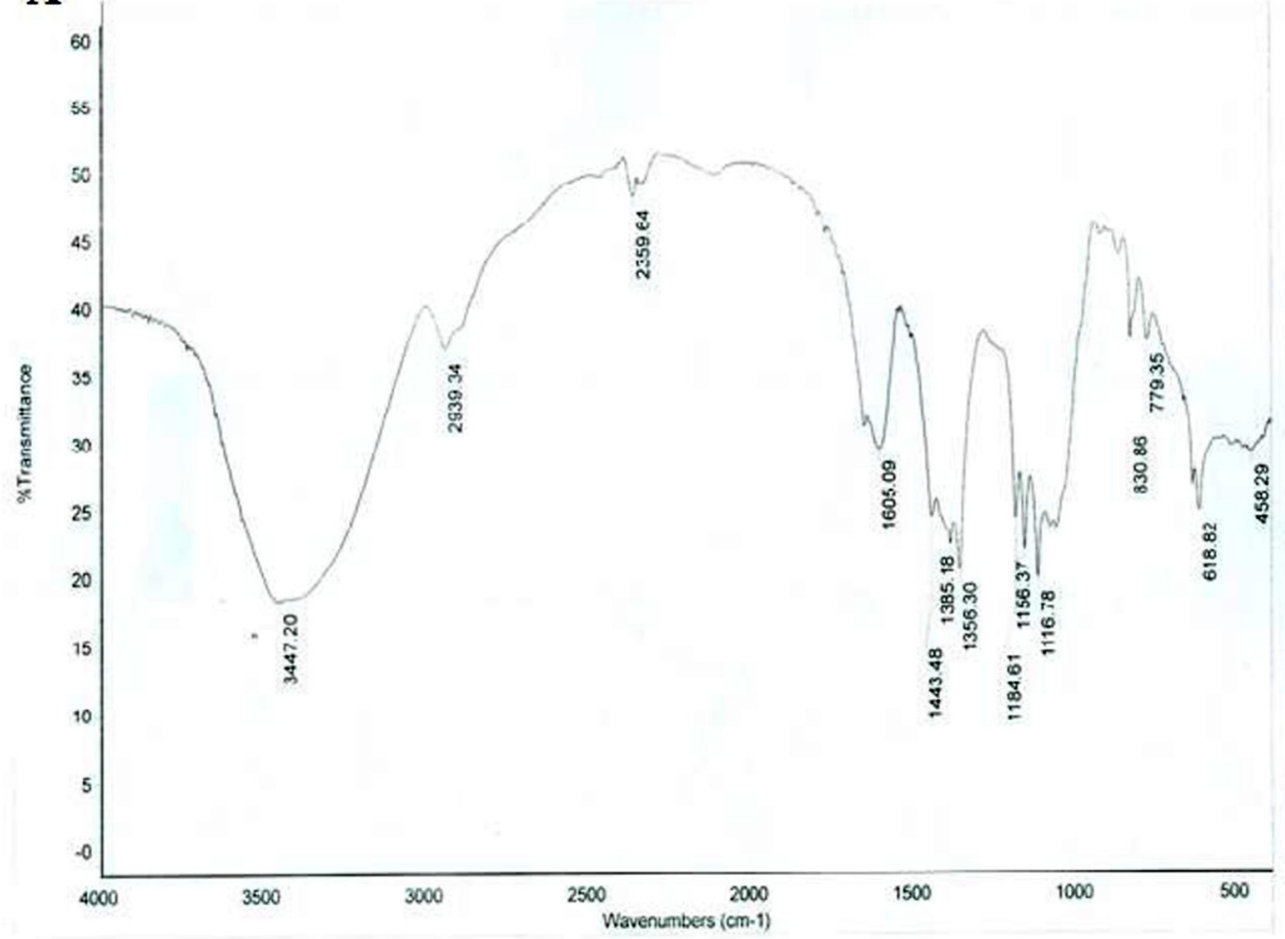

B

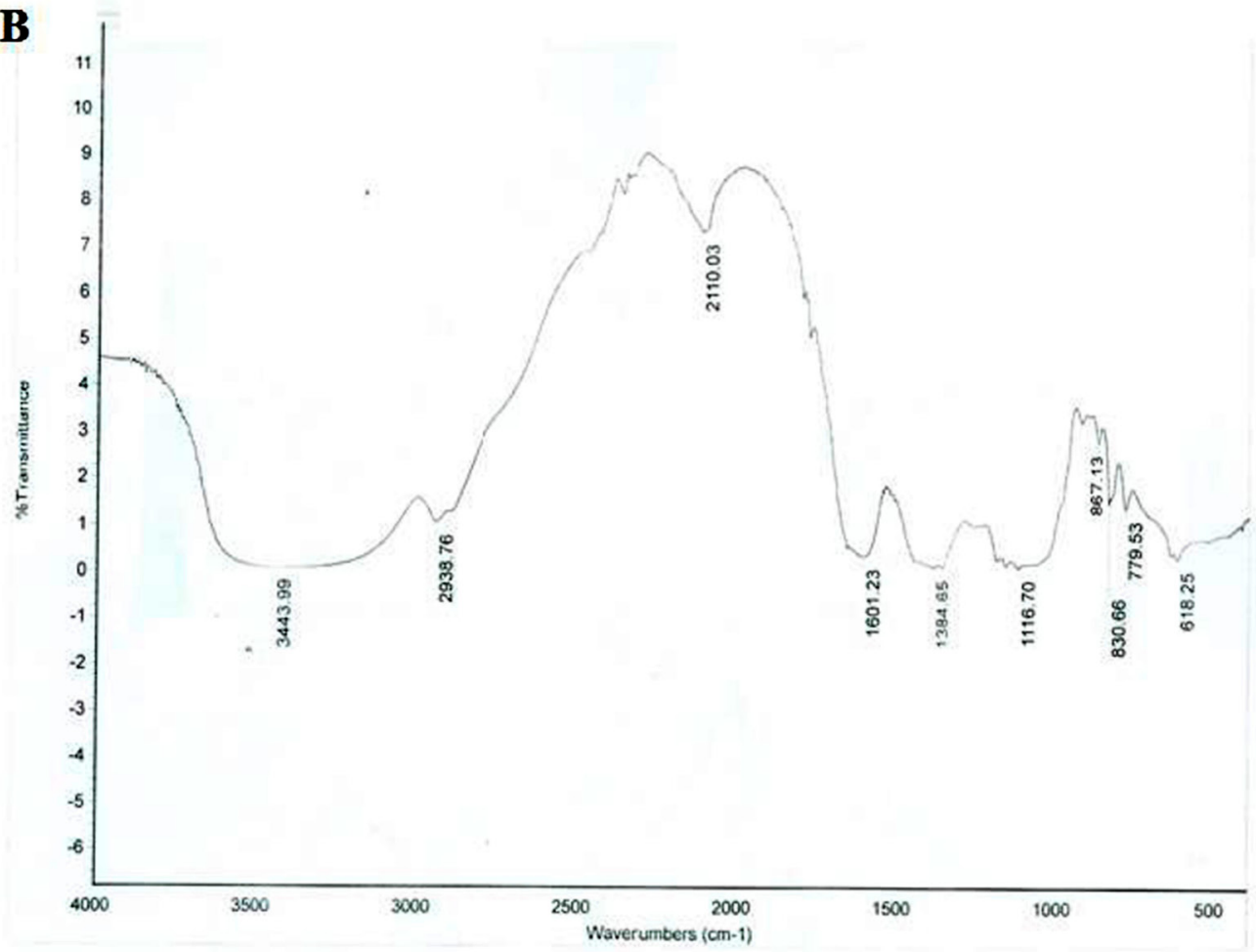

Fig. 9. FTIR spectra of zinc nanoparticles; A: Untreated amd B: Treated with $20 \mathrm{kGy}$ of gamma radiation. 


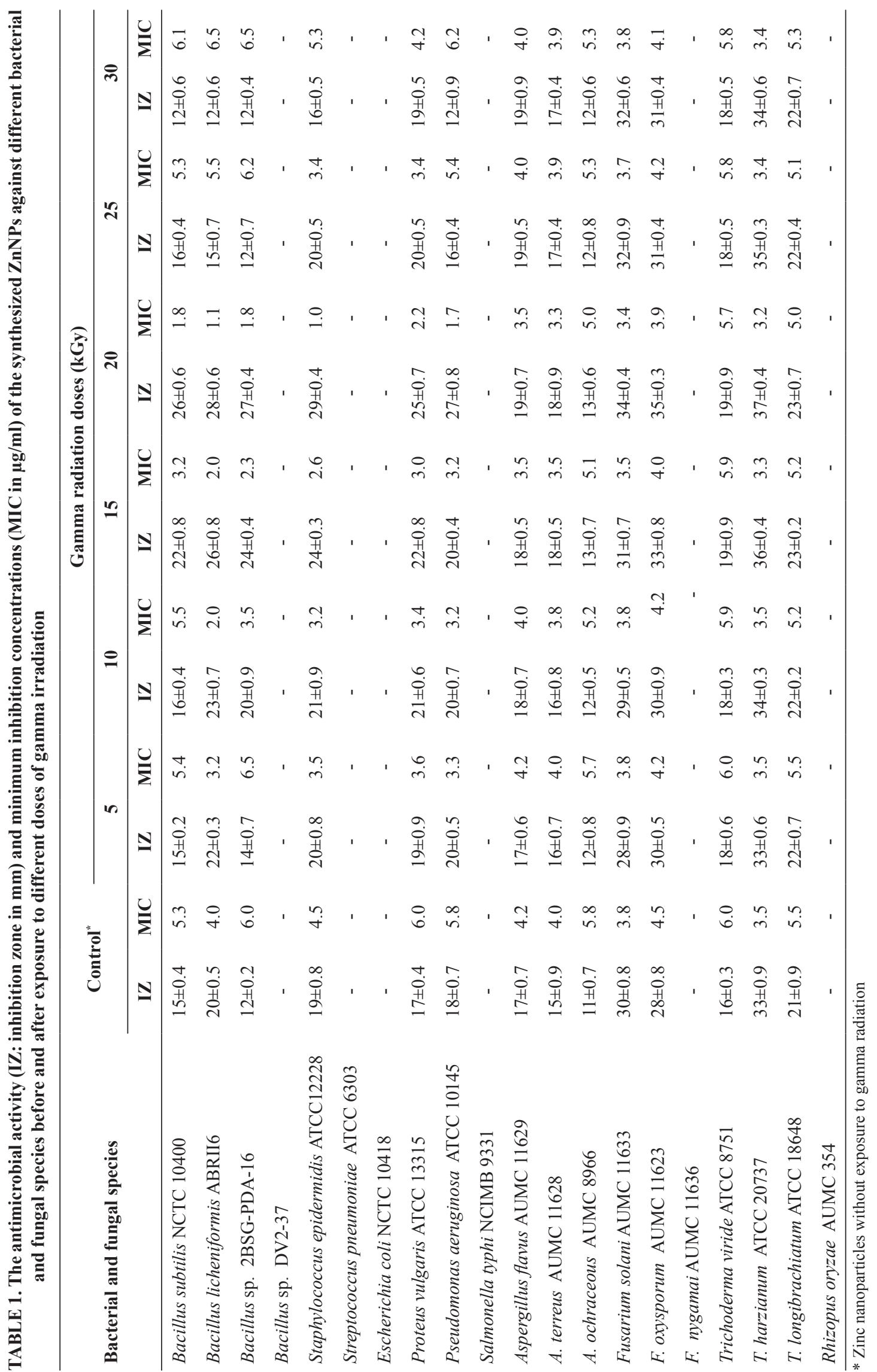

Egypt. J. Bot. 59 , No. 2 (2019) 
Various evidences suggest that zinc nanoparticles act as promising antimicrobial agents and may emerge as an alternative to conventional synthetic antibiotics. Similarly, the present study also supports the above fact. Interestingly, zinc nanoparticles exhibited good antifungal activity against all the tested pathogens even at low concentration and this is because of the stability of the synthesized zinc nanoparticles (Davood, 2013). It was suggested also by Sharma et al. (2007) that metallic nanoparticles are most promising because they contain remarkable antibacterial properties due to oligo dynamic nature of metal to inhibit the microbes as well as due to their large surface area to volume ratio.

The effect of $\gamma$ radiation on the antimicrobial activity of ZnNPs has been reported previously on $P$. aeruginosa and $K$. pneumoniae (El-molla et al., 2011), in this study, it was clear that applying $\gamma$ radiation on ZnNPs resulted in enhancing its antimicrobial activity against Streptococcus aureus, E. coli, Candida albicans, and $P$. aeruginosa. The effect of $\gamma$ irradiation may be due to its activation of $\mathrm{ZnNPs}$ and the production of $\mathrm{H}_{2} \mathrm{O}_{2}$ that can penetrate the microbial cell membrane and kill the bacteria (Fang et al., 2006 and Yousef \& Danial, 2012). Also, it may be due to the reduction in the specific surface area of the particles by irradiation, as reported for some solids. This possible size reduction was further tested by using DLS analysis and TEM.

Inhibitory effect of zinc nanoparticles exposed to different doses of gamma rays (from 5 to $30 \mathrm{kGy}$ ) against some pathogenic bacterial species was shown in Table 1. The results indicated that all the samples exhibited almost similar antibacterial efficacy but the sample exposed to $20 \mathrm{kGy}$ achieved the great inhibitory effect than others. The detailed mechanism of the bioactivity of ZnNPs is still under discussion. Many mechanisms have been proposed related to this; penetration of the nanoparticles causing destruction and damage of the cell membrane (Brayner et al., 2006), binding of zinc nanoparticles to the bacterial surface as a result of electrostatic forces causing directly bacterial cells damage (Stoimenov et al., 2002), the generation of highly reactive species such as $\mathrm{OH}, \mathrm{H}_{2} \mathrm{O}_{2}, \mathrm{O}_{2}{ }^{2-}$ (Sangeetha et al., 2012) and release of $\mathrm{Zn}^{2+}$ ions from the nanoparticles (Pasquet et al., 2014).

Few studies have showed that zinc nanoparticles may destroy fungal spores by destructing the membrane integrity. Other studies indicated that zinc nanoparticles may interact with sulphur containing compounds causing DNA and proteins damage and finally resulting in cell death. From this study, it is evident that zinc nanoparticles may have important applications in the agricultural sector and could be used as an effective antifungal agent against the harmful plant pathogens (Suwanboon et al., 2013). Zinc also is an essential element for inhibiting bacterial enzymes such as glutathione reductase, thiol peroxidase and dehydrogenase, so acting as an antibacterial agent (Rai et al., 2009).

\section{Antitumor activity}

In this work, we focus on ZnNPs synthesized using Penicillium chrysogenum and their potential anticancer behavior against the mice cell lines. Figure 10 shows antitumor activity of zinc nanoparticles at different concentrations (3.9, 7.8, 15.6, 31.25, 62.5, 125,250 and $500 \mu \mathrm{g}$ ) studied In vitro against human breast (MCF-7) and colon (HCT-116) carcinoma cell lines. ZnNPs treated with 20kGy showed higher cytotoxic potential against all cell lines in a dose-dependent manner than the untreated one. Cytotoxic activity was expressed as the mean $\mathrm{IC}_{50}$ of three independent experiments. As shown in Fig. 10, human breast (MCF-7) cells proliferation was significantly inhibited by ZnNPs with an $\mathrm{IC}_{50}$ values of $373 \pm 6.9 \mu \mathrm{g} / \mathrm{ml}$ and $>500 \mu \mathrm{g} / \mathrm{ml}$ for irradiated and non irradiated samples, respectively. Furthermore, colon (HCT-116) cells proliferation was significantly inhibited by $\mathrm{ZnNPs}$ with an $\mathrm{IC}_{50}$ values of $226 \pm 4.3$ and $317 \pm 9.7 \mu \mathrm{g} / \mathrm{ml}$ for irradiated and non irradiated samples, respectively. The small values of $\mathrm{IC}_{50}$ for the fungal $\mathrm{ZnNPs}$ prepared by the present method reveal higher and impressive efficiency as cytotoxic and anticancer drug. In this work we found biosynthesized ZnNPs to exhibit strong antitumor activity relative to other previously observed antitumor results (Damodaran \& Kavitha, 2015) and this effect was enhanced by the exposure of our synthesized ZnNPs to gamma rays especially the dose of $20 \mathrm{kGy}$.

Cancer is a dangerous, multistep and widely distributed disease. Oxidative damage as well as various physical, chemical, genetic and environmental factors can directly or indirectly induce its synthesis. There is always a need for new and effective agents for controlling this disease. Various reports revealed that zinc nanoparticles have important anti-angiogenic properties. Compounds with anti angiogenic properties may have antitumor activity as they have the ability to block the activity of abnormally expressed signaling protein (Premanathan et al., 2011). 


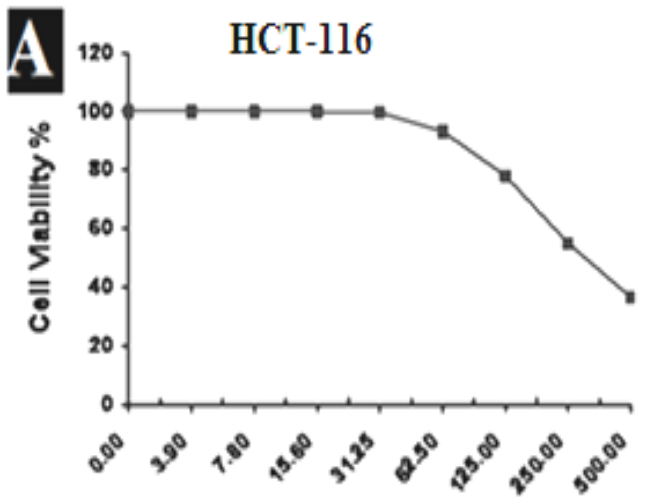

Concentration $(\mu \mathrm{g} / \mathrm{ml})$

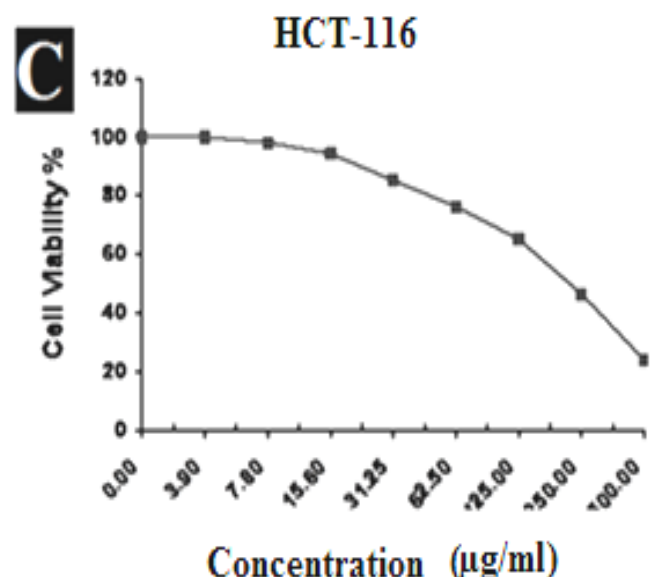

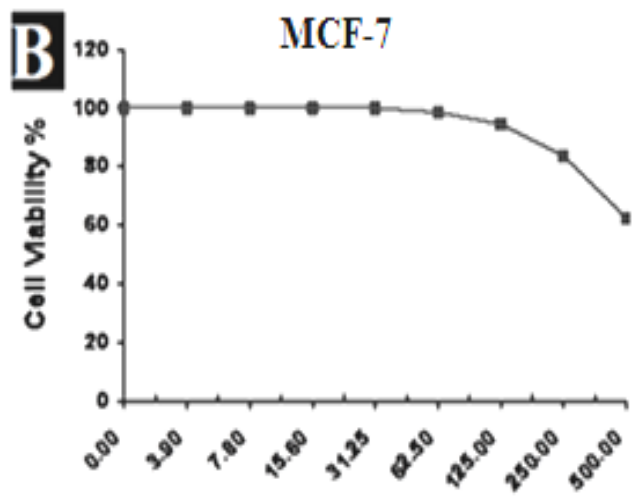

Concentration $(\mu \mathrm{g} / \mathrm{ml})$

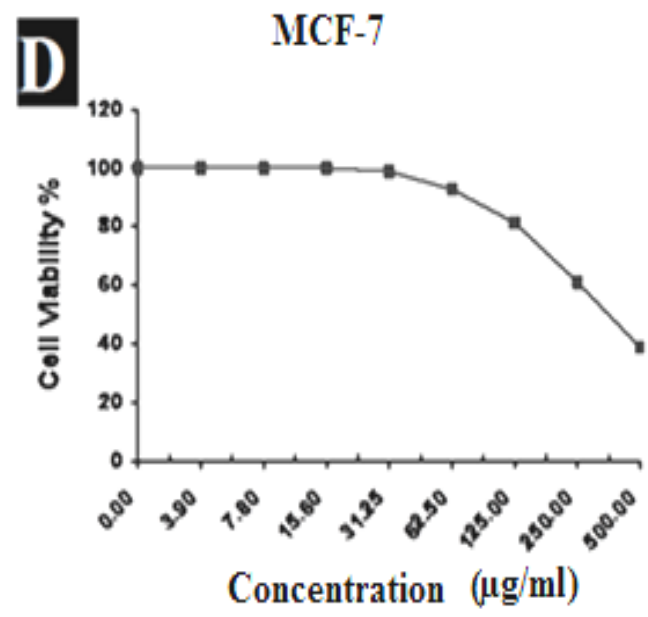

Fig. 10. Comparison between the cytotoxic activity of zinc nanoparticles treated with $20 \mathrm{kGy}$ of Gamma rays and untreated sample against colon (HCT-116) carcinoma cells; A: Treated, C: Untreated and against Breast (MCF-7) carcinoma cells; B: Treated and D: Untreated sample.

\section{Conclusion}

In this study, we present a low cost and rapid approach for the biosynthesis of zinc nanoparticles utilizing $P$. chrysogenum by the reduction of $\mathrm{ZnSO}_{4}$. Although, extensive studies have been carried out by researcher on the antimicrobial activity of ZnNPs, studies on the antimicrobial activity of $\mathrm{Zn}$ nanoparticles subjected to gamma irradiation are sparse. Morphology and characteristics of gamma irradiated ZnNPs has been investigated. The antimicrobial activity of gamma irradiated ZnNPs against some pathogenic bacterial and fungal species was reported. The average particle size was significantly decreased with increasing gamma irradiation doses. The FTIR studies confirm the characteristic peaks at $\sim 618 \mathrm{~cm}^{-1}$ for $\mathrm{Zn}-\mathrm{O}$ stretching. The current work indicates that gamma irradiation has led to an increase in the surface area which in turn has resulted in the improvement of antibacterial and antitumor potentials of ZnNPs.

\section{References}

Aguilar-Méndez, M.A., San Martín-Martínez, E., Ortega-Arroyo, L., Cobián-Portillo, G. and SánchezEspíndola, E. (2011) Synthesis and characterization of silver nanoparticles: Effect on phytopathogen Colletotrichum gloesporioides. Journal of Nanoparticle Research, 13(6), 2525-32.

Ahmad, A., Senapati, S., Khan, M.I., Kumar, R., Ramani, R.V. and Sastry, S.M. (2003) Intracellular synthesis of gold nanoparticles by a novel alkalotolerant actinomycete, Rhodococcus species. Nanotechnology, 14, 824-828.

Ahmad, M.B., Shameli, K. and Yunus, W.M.Z.W. (2010) Synthesis and characterization of silver/clay/starch bio-nano-composites by green method. Basic and Applied Sciences, 4, 2158-2165.

Ainsworth, G.C. (1971) "A Dictionary of Fungi". Commonwealth Mycological Institute, Kew, Surrey. 
Azam, A., Ahmed, A.S., Oves, M., Khan, M.S., Habib, S.S. and Memic, A. (2012) Antimicrobial activity of metal oxide nanoparticles against Gram-positive and Gram-negative bacteria: A comparative study. International Journal of Nanomedicine, 7, 60036009.

Banu, A. and Rathod, V. (2011) Synthesis and characterization of silver nanoparticles by Rhizopus stolonier. International Journal of Biomedical and Advance Research, 2(5), 148-158.

Baroli, B (2010) Penetration of nanoparticles and nanomaterials in the skin: fictionorreality? Journal of Pharmaceutical Sciences, 99(1), 21-50.

Basavaraja, S., Balaji, S., Lagashetty, K., Rajasab, H. and Venkataraman, A. (2008) Extracellular biosynthesis of silver nanoparticles using the fungus Fusarium semitectum. Materials Research Bulletin, 43, 11641170.

Boxall, P., Purcell, J. and Wright, P. (2007) Human Resource Management: scope, analysis and significance. "The Oxford Handbook of Human Resource Management", Oxford: Oxford University Press.

Brayner, R., Ferrarilliou, R., Brivois, N., Djediat, S., Benedetti, M.F. and Fievet, F. (2006) Toxicological impact studies based on Escherichia coli bacteria in ultrafine $\mathrm{ZnO}$ nanoparticles colloidal medium. Nano Letters, 6, 866-870.

Cai, S. and Singh, B.R. (2004) A distinct utility of the amide III infrared band for secondary structure estimation of aqueous protein solutions using partial least squares methods. Biochemistry, 43, 2541-2549.

Damodaran, M. and Kavitha, S. (2015) Anticancer activity of zinc nanoparticles made using terpenoids from aqueous leaf extract of Andrographis Paniculata. International Journal of Pharmaceutical Sciences and Nanotechnology, 8, 3018.

Davood, R. (2013) Synthesis and microstructural properties of $\mathrm{ZnO}$ nanoparticles prepared by precipitation method. Renewable Energy, 50, 932937.

Dey, G., El Omar, A., Jacob, J., Mostafavi, M. and Belloni, J. (2010) Mechanism of trivalent gold reduction and reactivity of transient divalent and monovalent gold ions studied by gamma and pulse radiolysis. Journal of Physical Chemistry A, 115, 383-391.

EL-Khatib, A.A., Hegazy, A.K. and Galal, H.K. (2004) Allelopathy in the rhizosphere and amended soil of Chenopodium murale L. Weed Biology and Management, 4, 35-42.

El-molla, S.A., Ismail, S.A. and Ibrahim, M.M. (2011) Effect of gamma irradiation and aging on surface and catalytic activity of nanosized $\mathrm{CuO} / \mathrm{MgO}$ system. Journal of the Mexican Chemical Society, 55(3), 154-163.

Fang, M., Chen, J.H., Xu, X.L., Yang, P.H. and Hildebr, H.F. (2006) Antibacterial activities of inorganic agents on six bacteria associated with oral infections by two susceptibility tests. International Journal of Antimicrobial Agents, 27, 513-517.

Gericke, M. and Pinches, A. (2006) Biological synthesis of metal nanoparticles. Hydrometallurgy, 83(1), 132-140.

Gomha, S.M., Riyadh, S.M., Mahmmoud, E.A. and Elaasser, M.M. (2015) Synthesis and anticancer activities of thiazoles, 1,3-thiazines, and thiazolidine using chitosan-grafted-poly (vinylpyridine) as basic catalyst. Heterocycles, 91(6), 1227-1243.

Gong, J.L., Liang, Y., Huang, Y., Chen, J.W., Jiang, J.H., Shen, G.L. and Yu, R.Q. (2007) Ag/ $\mathrm{SiO}_{2}$ coreshell nanoparticle-based surface-enhanced Raman probes for immune assay of cancer marker using silica-coated magnetic nanoparticles as separation tools. Biosensors and Bioelectronics, 22(7), 15011507.

John, W.R., Ezequiel, M., Panagiota, L. and Denise, G.W. (2010) Zinc oxide nanoparticles for selective destruction of tumor cells and potential for drug delivery applications. Expert Opinion on Drug Delivery, 7(9), 1063-1077.

Jones, N., Ray, B., Ranjit, K.T. and Manna, A.C. (2008) Antibacterial activity of $\mathrm{ZnO}$ nanoparticle suspensions on a broad spectrum of microorganisms. FEMS Microbiology Letters, 279, 71-76.

Pasquet, J., Chevalier, Y., Pelletier, J., Couval, E., Bouvier, D. and Bolzinger, M.A. (2014) The contribution of zinc ions to the antimicrobial activity of zinc oxide Colloids Surfaces A. Physicochemical and Engineering Aspects, 457, 263-274. 
Khadri, H., Alzohairy, M., Janardhan, A., Kumar, A.P. and Narasimha, G. (2013) Green synthesis of silver nanoparticles with high fungicidal activity from olive seed extract. Advances in Nanoparticles, 2(3), 241.

Li, M., Bala, H., Lv, X., Ma, X., Sun, F., Tang, L. and Wang, Z. (2007) Direct synthesis of monodispersed $\mathrm{ZnO}$ nanoparticles in an aqueous solution. Materials Letters, 61, 690-69.

Liu, Y., Chen, S., Zhong, L. and Wu, G. (2009) Preparation of high-stable silver nanoparticle dispersion by using sodium alginate as a stabilizer under gamma radiation. Radiation Physics and Chemistry, 78, 251-255.

Lu, P.J., Huang, S.C., Chen, Y.P., Chiueh, L.C. and Shih, D.Y. (2015) Analysis of titanium dioxide and zinc oxide nanoparticles incosmetics. Journal of Food and Drug Analysis, 23(3), 587-594.

Mahmoud, A.M., Ahmed, O.M., Abdel-Moneim, A. and Ashour, M.B. (2013) Upregulation of PPAR $\gamma$ mediates the antidiabetic effects of citrus flavonoids in high fat diet fed-streptozotocin induced type 2 diabetic rats. International Journal of Bioassays, 2 , 756-761.

Markushev, V.M., Ryzhkov, M.V., Briskina, C.M. and Cao, H. (2005) UV radiation of powdered $\mathrm{ZnO}$ pumped by nanosecond pulses. Laser Physics, 15(12), 1611-1616.

Misra, N., Biswal, J., Gupta, A., Sainis, J. and Sabharwal, S. (2012) Gamma radiation induced synthesis of gold nanoparticles in aqueous polyvinyl pyrrolidone solution and its application for hydrogen peroxide estimation. Radiation Physics and Chemistry, 81, 195-200.

Nagarajan, S. and Kuppusamy, K.A. (2013) Extracellular synthesis of zinc oxide nanoparticle using seaweeds of gulf of Mannar. Indian Journal of Nanobiotechnology, 1(1), 1.

Naik, L.S., Marx, K.P., Sree Vennela, P. and Devi, C.V. (2013) Green synthesis of silver nanoparticles using Strawberry leaf extract (Arbutus unedo) and evaluation of its antimicrobial activity-a Novel study. International Journal of Nanomaterials and Biostructures, 3, 47-50.

Nicole, V., Nguyen, K. and Kupiec, T.C. (2014)
The essentials of United States pharmacopeia, chapter $<51>$, antimicrobial effectiveness testing. International Journal of Pharmaceutical Compounds, 18(2), 123-130.

Noorjahan, C.M., Jasmine Shahina, S.K., Deepika, T. and Summera, R. (2015) Green synthesis and characterization of zinc oxide nanoparticles from Neem (Azadirachta indicia). International Journal of Scientific Engineering and Technology Research, 4(30), 5751-5753.

Ostrovsky, S., Kazimirsky, G., Gedanken, A. and Brodie, C. (2009) Selective cytotoxic effect of $\mathrm{ZnO}$ nanoparticles on glioma cells. Nano Research, 2, 882-890

Padmavathy, N. and Vijayaraghavan, R. (2008) Enhanced bioactivity of $\mathrm{ZnO}$ nanoparticles- an antimicrobial study. Science and Technology of Advanced Materials, 9, 1-7.

Perez, C., Paul, M., and Bazerque, P. (1990) Antibiotic assay by agar well diffusion method. Actabiologiae et Medicinae Experimentali, 15, 113-115.

Pitt, J.I. (1979) "The Genus Penicillium and its Teleomorphic States Eupenicillium and Talaromyces. 634 S., 132 Abb". London-New YorkToronto-Sydney-San Francisco 1979. Academic Press.

Premanathan, M., Karthikeyan, K., Jeyasubramanian, K. and Manivannan, G. (2011) Selective toxicity of $\mathrm{ZnO}$ nanoparticles toward gram positive bacteria and cancer cells by apoptosis through lipid peroxidation. Nanomedicine, 7, 184-192.

Rai, M., Yadav, A. and Gade, A. (2009) Silver nanoparticles as a new generation of antimicrobials. Biotechnology Advances, 27(1), 76-83.

Rajamanickam, U., Mylsamy, P., Viswanathan, S. and Muthusamy, P. (2012) Biosynthesis of zinc nanoparticles using actinomycetes for antibacterial food packaging. In: International Conference on Nutrition and Food Sciences IPCBEE (Vol. 39).

Renugadevi, K. and Venus, A.R. (2012) Microwave irradiation assisted synthesis of silver nanoparticle using Azadirachtaindica leaf extract as a reducing agent and in vitro evaluation of its antibacterial and anticancer activity. International Journal of Nanomaterials and Biostructures, 2, 5-10. 
Renuga, D.T.S. and Gayathri, S. (2010) FTIR and FT-Raman spectral analysis of paclitaxel drugs. International Journal of Pharmaceutical Sciences Review and Research, 2, 106-110.

Sahayaraj, K. and Rajesh, S. (2011) Bionanoparticles: synthesis and antimicrobial applications. Science against microbial pathogens. Communicating Current Research and Technological Advances 228-44.

Sangeetha, G., Rajeshwari, S. and Venckatesh, R. (2011) Green synthesis of zinc oxide nanoparticles by Aloe barbadensis miller leaf extract: Structure and optical properties. Materials Research Bulletin, 46, 2560-2566.

Sangeetha, G., Rajeshwari, S. and Venckatesh, R. (2012) Green synthesized $\mathrm{ZnO}$ nanoparticles against bacterial and fungal pathogens. Progress in Natural Science: Materials International, 22, 69370.

Sanghi, R. and Verma, P. (2008) Biomimetic synthesis and characterization of protein capped silver nanoparticles. Bioresource Technology, 100(1), 501-504.

Schauermann, S., Nilius, N., Shaikhutdinov, S. and Freund, H. (2013) Nanoparticles for heterogeneous catalysis: New mechanistic insights. Accounts of Chemical Research, 46, 1673-1681.

Sharma, N.C., Sahi, S.V., Nath, S., Parsons, J.G., Gardea-Torresdey, J.L. and Pal, T. (2007) Synthesis of plant - mediated gold nanoparticles and catalytic role of bio matrix-embedded nanomaterials. Environmental Science Technology, 41, 5137-5142.

Singh, G., Joyce, E.M., Beddow, J. and Mason, T.J. (2012) Evaluation of antibacterial activity of $\mathrm{ZnO}$ nanoparticles coated sonochemically onto textile fabrics. Journal of Microbiology, Biotechnology and Food Sciences, 2(1), 106-120.

Singh, B.N., Rawat, A.K.S., Khan, W., Naqvi, A.H. and Singh, B.R. (2014) Biosynthesis of stable antioxidant $\mathrm{ZnO}$ nanoparticles by Pseudomonas aeruginosa rhamnolipids. PLoS One, 9, e106937.

Soliman, Y. (2014) Gamma-radiation induced synthesis of silver nanoparticles in gelatin and its application for radiotherapy dose measurements. Radiation Physics and Chemistry, 102, 60-67.
Stoimenov, P.K., Klinger, R.L., Marchin, G.L. and Klabunde, K.J. (2002) Metal oxide nanoparticles as bactericidal agents. Langmuir, 18, 6679-6686.

Suwanboon, S., Amornpitoksuk, P., Sukolrat, A. and Muensit, N. (2013) Optical and photocatalytic properties of La-doped $\mathrm{ZnO}$ nanoparticles prepared via precipitation and mechanical milling method. Ceramics International, 39, 2811-2819.

Thakkar, K.N., Mhatre, S.S. and Parikh, R.Y. (2010) Biological synthesis of metallic nanoparticles. Nanomedicine. Nanotechnology, Biology and Medicine, 6, 257-262.

Waghmare, S.S., Deshmukh, A.M., Kulkarni, S.W. and Oswaldo, L.A. (2011) Biosynthesis and characterization of manganese and zinc Nanoparticles. Universal Journal of Environmental Research \& Technology, 1(1).

Wang, C., Liu, L., Zhang, A., Xie, P., Lu, J. and Zou, $X$. (2012) Antibacterial effects of zinc oxide nanoparticles on Escerichia coli K 88. African Journal of Biotechnology, 11(44), 10248-10254.

Xie, J., Lee, J.Y., Wang, D.I.C. and Ting, Y.P. (2007) High-yield synthesis of complex gold nanostructures in a fungal system. The Journal of Physical Chemistry, C 111, 16858-16865.

Yousef, J. and Danial, E. (2012) In vitro antibacterial activity and minimum inhibitory concentration of zinc oxide and nano-particle zinc oxide against pathogenic strains. Journal of Health Science 2(4), $38-42$.

Zhang, Y., Nayak, T.R., Hong, H. and Cai, W. (2013) Biomedical applications of zinc oxide nanomaterials. Current Molecular Medicine, 13(10), 1633-1645.

Zhou, Z., Son, J., Harper, B., Zhou, Z. and Harper, S. (2015) Influence of surface chemical properties on the toxicity of engineered zinc oxide nanoparticles to embryonic zebra fish. Beilstein Journal of Nanotechnology, 6(1), 1568-1579.

(Received 7/10/2018; accepted 13/1/2019) 


\section{تحسين النشاط المضاد للميكروبات والمضاد للأورام السرطانية لحبيبات الزنك النانوية

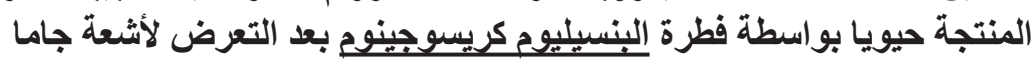 \\ منال ماهر حسينى و إيمان زكريا جمعة لئه

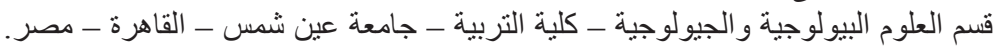

خلال هذة الدر اسة نم تنفيذ بروتوكول صديق للبيئة للتخليق الحيوي لحبيبات الزنك النانوية (ZnNPs) خارج

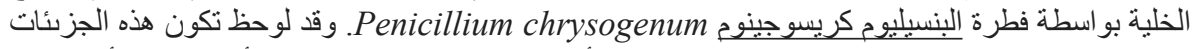

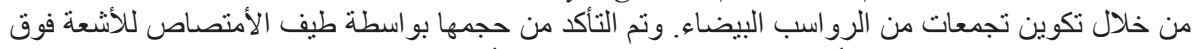

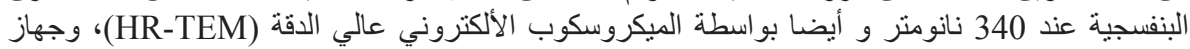

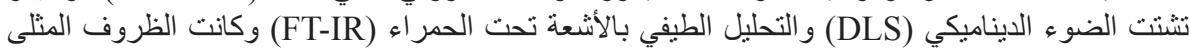

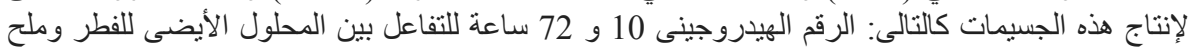

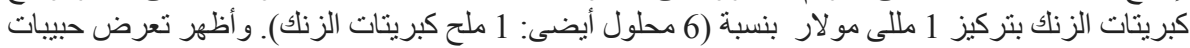

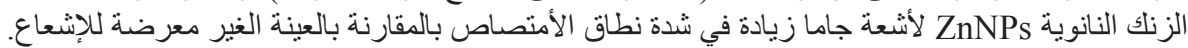

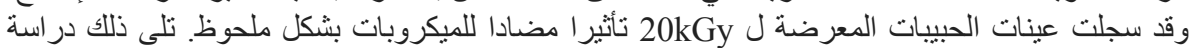

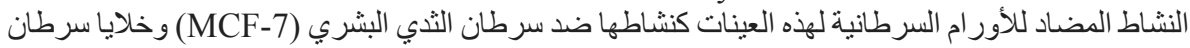

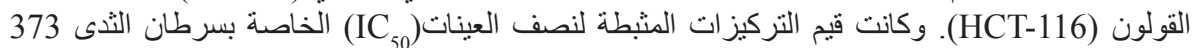

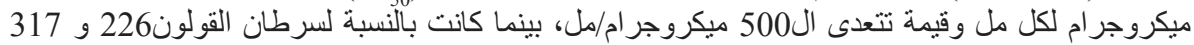

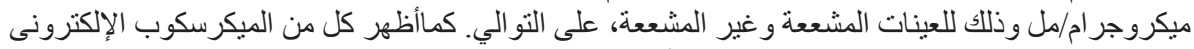

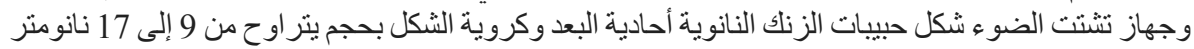

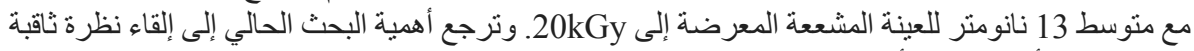

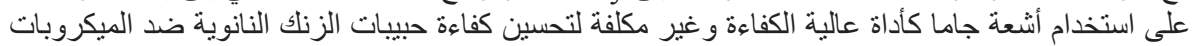
وكذللك ضد الأمر اض المعدية والمان الأورام. 